Journal of Sustainable and Manufacturing in Transportation

\title{
The Effect of Design Parameters on Mechanical Characteristics of Porous CoCrMo Scaffold Manufactured by Additive Manufacturing
}

\author{
Siti Rohaida Mohamed ${ }^{1}$, Saiful Anwar Che Ghani ${ }^{*}$, Worapoong Sawangsri ${ }^{2}$, \\ Mohd Azwan Azizi ${ }^{3}$
}

${ }^{1}$ Human Engineering Group, Faculty of Mechanical Engineering,

Universiti Malaysia Pahang, MALAYSIA

${ }^{2}$ Department of Electro-Mechanical Manufacturing,

Kasetsart University, THAILAND

${ }^{3}$ Zauber Engineering Sdn Bhd,

Jalan Mega A, Bandar Teknologi Kajang, 43500 Semenyih, Selangor MALAYSIA

DOI: https://doi.org/10.30880/jsmt.2021.01.01.006

Received 24 August 2021; Accepted 11 October 2021; Available online 15 December 2021

\begin{abstract}
Metallic orthopedic implants to replace or generate lost bones caused by traumatic road traffic injuries often failed prematurely after surgery. Bone resorption caused by stress shielding of metallic implants became a main concern as it can potentially lead to bone implant failure. Metallic scaffold designed in porous structures fabricated using additive manufacturing (AM) are widely used as bone implant, since the elastic modulus of the scaffolds can easily tailored according to the bone properties, and the large surfaces are beneficial to cell ingrowth. The microarchitecture of scaffold can control their mechanical and biological properties, but it is found that there is lack of systematic approach to select a cell topology with full perspective requirements of bone implant. This paper presents a systematic approach of design space mapping for two CoCrMo unit cell shapes namely square and diamond to understand the relationship between geometrical parameters with additive manufacturing limitation, mechanical and bone ingrowth requirements. The compressive response of the components was simulated by finite element analysis and the influence of design parameters on the scaffold behaviour was compared theoretically with Gibson and Ashby model. The FEA give prediction for effective elastic modulus of $3 \mathrm{GPa}$ to $4.8 \mathrm{GPa}$ for diamond type and range of $6 \mathrm{GPa}$ to $29 \mathrm{GPa}$ for square type. Experimental results showed accurate prediction of compression elastic modulus with average error of $13 \%$ for diamond type and $35 \%$ for square type respectively. The significance of the methodology and the results showed that different design parameters of the structures can play a major role in the mechanical behaviour of the metallic scaffold.
\end{abstract}

Keywords: Metallic scaffold, bone implant, additive manufacturing, design space, FEA, CoCrMo

\section{Introduction}

Effect of road traffic injures (RTIs) is significantly high contribution to deaths and injuries and are responsible for more lost years of life than most human diseases [1]. Porous metallic scaffold are commonly used in bone regenerative medicine and orthopaedic implant to replace damaged bone tissue and to restore its functionality [2, 3]. Orthopedic fractures including oral and maxillofacial fractures were the most common injuries among inpatients due to road traffic accidents (RTA) in Taiwan from 2002 to 2011, whereas approximately four injuries recorded every hour in Saudi Arabia [4]. 
Co-Cr-Mo alloys are one of the most important biomaterials used in bone implant, dental and tissue engineering due to their high strength, wear, fracture toughness and corrosion resistance $[5,6]$.

Porous scaffold with controlled modulus can be applied to improve mechanical stability and increase flexibility for better biological response with bone tissue. The function and overall performance of scaffold rely upon the careful selection of cell topology, porosity interconnectivity, pore shape and size, each affecting load-bearing capacity, mechanical stability and rate of bone ingrowth [7,8]. Countless literatures have been published reporting optimum pore size range to promote and support biological response in bone tissue regenerative implants [9, 10]. In summary, optimum pore size for in vivo bone regeneration is bigger than $500 \mu \mathrm{m}$ whereas, bigger pore size allowed proper new blood vessel formation [11-13]. Meanwhile, the optimum pore size for in vitro is in the range $50 \mu \mathrm{m}$ to $400 \mu \mathrm{m}$ [14, 15] . The smaller pore size was better for initial adhesion, cell proliferation and differentiation [16].

However, the rationally design and fabrication technique of the scaffold can be a challenge in order to considered their both mechanical and biological response. A variety of approaches were developed to produce porous scaffold with homogenous pore distribution and high degree of porosity interconnectivity [17-20]. The structures with a defined pore size with a specific porosity gradient are difficult to achieve since no agreement on quantitative criteria specifying cell topologies parameters for optimum mechanical and biological responses [21, 22].

In parallel of reliable additive manufacturing (AM) technologies, the fully porous scaffolds with controlled architecture and desirable functional are enable to manufacture [23, 24]. Selecting a cell topology without systematic approach always leads to the design of scaffold with pore size range bigger than optimum range for bone ingrowth requirements $[25,26]$. Furthermore, the thickness limitation of additive manufacturing process can affect the admissible design range of scaffold topologies parameters [27, 28].

Finite element analysis (FEA) is a cost and time effective tool to predict and evaluate the mechanical properties of different porous structures at the macroscale and mesoscale level [29, 30]. Wang, et al. [31] found that effective elastic modulus via FEA modelling was increasing with increased diameter of the internal strut where diameter of strut 0.3 $\mathrm{mm}$ and corresponded to a porosity $80 \%$ was found to be comparable to the human cortical bone. Similarly, Gao, et al. [32] reported that the maximum von Mises stresses of porous structures were gradually decreased along with the increasing strut size. However, the structures with strut diameter $0.8 \mathrm{~mm}$ provided a good load transfer to bone tissue while resisting the mechanical failure.

This paper presents a systematic visualization methodology to understand the interplay between topological parameters of designed scaffold with mechanical and biological requirements for optimum performances. This approach enables the generation design space mapping contribute of pore size, porosity, unit cell size, strut thickness with the constraints of both manufacturing limitation and bone ingrowth requirements. The methodology is applied and demonstrated in this paper with two different unit cells namely diamond and square that represented bendingdominated and stretch-dominated cell type. Structural designs were simulated using finite element analysis (FEA) to predict the morphology parameters on the structures effective stiffness. The selected samples were fabricated by additive manufacturing and undergone compression test for FEA validation.

\section{Methodology}

\subsection{Development of Design Space Domains}

The mechanical properties and biological behaviour of a unit cell for meta-biomaterials are regulated by the topology features such as interconnectivity, pore shape, pore size, porosity, strut thickness, and used biomaterials. However, the way stated morphological geometries influence the mechanical and biological properties are not certainly intuitive. Thus, this paper develops a parametric model to illustrate the geometry of a unit cell and afterwards use it to visualize its morphological properties on a design chart. The chart model allows to visually examining what porosity and pore size combination exist and are possible to fabricate.

In this study, diamond and square unit cell are selected, which their parametric geometric models are used to generate the design domains. Both of unit cells have a stiffness matrix with a cubic symmetry and they exhibit nearly isotropic mechanical properties. From the given geometric topology, a computer aided design (CAD) model is generated for each selected unit cell. The overall unit cell type is controlled by two parameters which are strut thickness (t) and unit cell size (l). Each unit cell can be scaled through these parameters combination to obtain resultant of desired porosity and pore size. In this study, the pore size is define by largest circle correspond that can pass between neighbouring cells in meta-biomaterials structure. The porosity is measured from the percentage of void on fully solid cells as in Equation 1.

$$
\text { Porosity }(\%)=\left(1-V_{p} / V_{s}\right) \times 100
$$

where $\mathrm{V}_{\mathrm{p}}$ is the volume if the porous unit cell and $\mathrm{Vs}$ is the volume of the fully solid unit cell. 
The resultant pore size and porosity can be plot in contour maps with pore size on the $\mathrm{x}$ axis and strut thickness on the $y$ axis. Meanwhile, the value of cell size and porosity are illustrated as isometric lines. The visualization model can help to understand of the relationship between the geometrical parameters of a unit cell. From the contour area, the following bone in-growth requirement and manufacturing limits can be overlaid to highlight the admissible design space. The vital criteria for generating design space are as follows;

- Bone in-growth requirement: pore size between 50 and $800 \mu \mathrm{m}$ with porosity higher than $50 \%$ are favorable for optimum biological response [33-35]. These values are illustrated as red lines in the design space chart

- Manufacturing constraint: Additive manufacturing (AM) technologies are limited to produce a nominal strut thickness of $200 \mu \mathrm{m}$ of meta-biomaterials depending to selected process parameters [36, 37]. The line constraint is included in the design space chart as a horizontal red line.

\subsection{Selection of Design Representation Samples}

The triangular design domain emerges with boundaries as in the blue area represents value of its geometric parameters with respect to appropriate for bone in-growth and manufacture capability of AM technology. All the designs of meta-biomaterials falling within the domains area are satisfactory solutions that emerge the bone in-growth requirements and AM limitations. The design space for this study is illustrated in Fig. 1.

Representative points (in black) at the boundary region of the domain are selected for prediction of effective elastic modulus. For diamond unit cell, seven points are selected where the porosity is in range of 50\% to $80 \%$ (points Diamond \#1-7). Meanwhile, for square unit cell, six points are selected in the range of porosity of 50\% to $70 \%$ (point Square \#1-6). These points allow for a direct comparison of the effect of cell topology across unit cell length, pore size and porosity with morphology corresponding to ideal requirement of orthopedic implants. The morphological details for the selected points are summarized in Table 1.

\subsection{Finite Element Analysis}

In order to obtain a prediction of the effective elastic modulus $\left(\mathrm{E}_{\text {eff }}\right)$ of selected design points, a model proposed by was utilized and calculated using equation 1 where the elastic modulus of solid material for CoCrMo is $220 \mathrm{GPa}$.

$$
E^{*} / E_{s}=C\left(\rho^{*} / \rho_{s}\right)^{2}
$$

where: $E^{*}$ is elastic modulus of design samples, Es is elastic modulus of solid material, C is constant, $\rho$ *is density of cellular structure and $\rho_{\mathrm{s}}$ density of solid material. From the equation 1 , it is proven that the elastic modulus is dependent upon the relevant density and density can be related to porosity by equation 2 where $\varphi$ is porosity.

$$
\left(\rho^{*} / \rho_{s}\right)=1-\varphi
$$

Therefore the equation 2 can be rewritten as equation 3 to calculate the effective elastic modulus where $\mathrm{E}_{\text {eff }}$ effective elastic modulus

$$
\left.E_{e f f}=E_{s}(1-\varphi)^{2}\right)
$$

Originally, the Gibson and Ashby model was developed to predict the elasticity of a three dimensional open cellular which is effective elastic modulus $\left(E_{\text {eff }}\right)$ structure when the structure was loaded vertically upon unit cell geometry that is similar in this research study to determine the mechanical properties. 

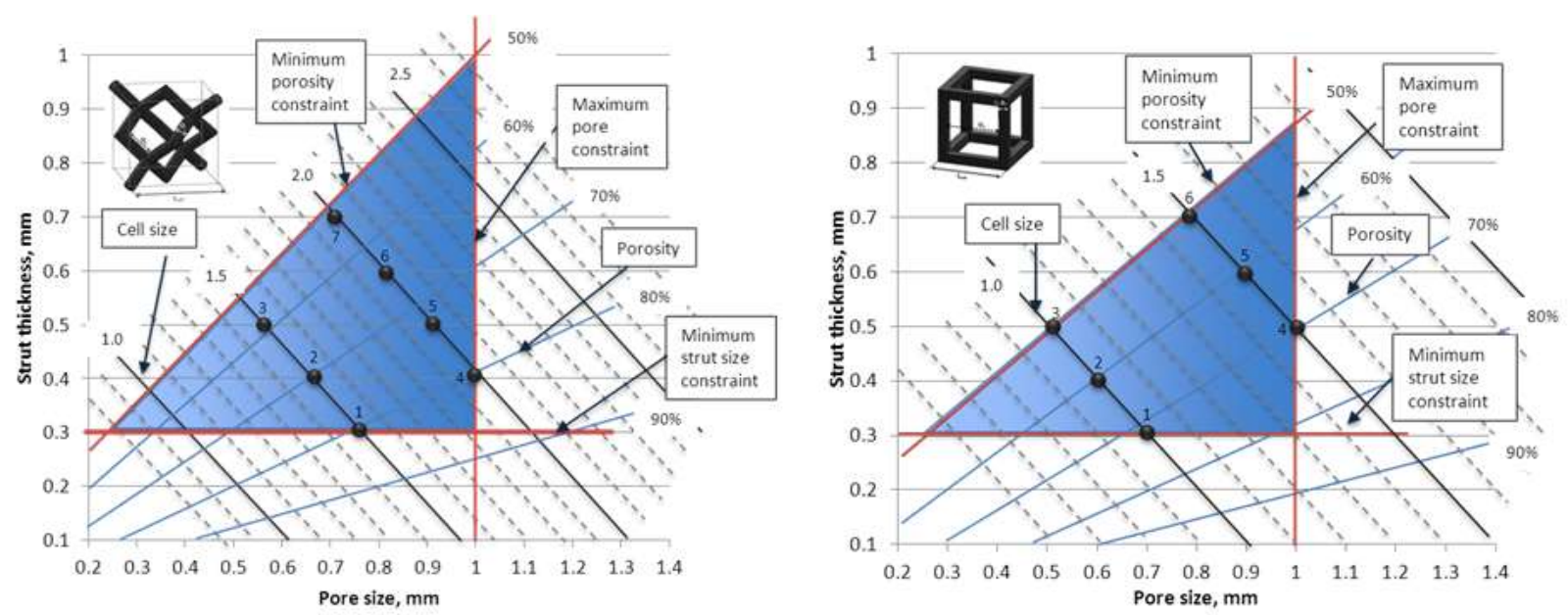

Fig. 1 - Admissible design space (a) diamond; (b) square type meta-biomaterials

ANSYS 18.0 finite element modelling software was used to predict the effective elastic modulus of the selected design points. The software was also used to perform a simulation that considered the effect of variation within a porous component in order to investigate what effect this had on the effective stiffness. The finite element model was employed for compression due to the need of a detailed response at the mesoscale. In order to prevent high CPU times for solving numerical model, considering the geometry symmetry of the design structure, one tower of the structure containing six layers with one cell in each layer was chosen to perform the finite element analysis. The FEA model in this study were similar to the previous study by [38].

The FEA models were given the input material properties of medical graded CoCrMo alloys as shown in the Table 2. Each model was meshed using SOLID 185 four node tetrahedral elements. An element of $0.1 \mathrm{~mm}$ was used in each simulation. 3D finite element analysis quasi-static simulations were performed. Boundary condition in which a uniform $0.01 \%$ compressive strain was applied within the material elastic limit to top face of the structure, whereas the bottom surface was fully fixed in the all degree of freedom. No boundary constraints were applied to the sides of the design structures. The applied boundary conditions in this study adopted by previous study by [39]. The uniformity of the von Mises stress distribution within the struts was computed and the average stress was evaluated

\subsection{Material and Manufacturing}

The selected samples for validation were produced using SLM 125HL with the building direction as shown in Fig. 2. A $300 \mathrm{~W}$ laser with energy density of $119 \mathrm{~J} / \mathrm{mm}^{3}$ and scan spacing diameter of $0.12 \mathrm{~mm}$ was used for manufacturing selected samples for finite element justification. The representative samples are made by medical graded CoCrMo due to their excellent corrosion resistance and fracture toughness with average size of powder particle was $25 \mu \mathrm{m}$ and the layer thickness during SLM process was $30 \mu \mathrm{m}$. The samples were processed for post treatment at $1100{ }^{\circ} \mathrm{C}$ for 2 hours under argon environment and were removed from built plate using EDM wire cutting.

Table 1 - Geometrical detail of the selected design samples

\begin{tabular}{lllll}
\hline $\begin{array}{l}\text { Unit } \\
\text { cell }\end{array}$ & $\begin{array}{l}\text { Unit cell } \\
\text { length } \\
(\mathrm{mm})\end{array}$ & $\begin{array}{l}\text { Strut size } \\
(\mathrm{mm})\end{array}$ & $\begin{array}{l}\text { Pore size } \\
(\mathrm{mm})\end{array}$ & $\begin{array}{l}\text { Porosity } \\
(\%)\end{array}$ \\
\hline D1 & 1.5 & 0.3 & 0.76 & 82 \\
D2 & 1.5 & 0.4 & 0.66 & 70 \\
D3 & 1.5 & 0.5 & 0.56 & 58 \\
D4 & 2.0 & 0.4 & 1.1 & 80 \\
D5 & 2.0 & 0.5 & 0.91 & 74
\end{tabular}




\begin{tabular}{lllll} 
D6 & 2.0 & 0.6 & 0.81 & 66 \\
D7 & 2.0 & 0.7 & 0.71 & 54 \\
S1 & 1.0 & 0.3 & 0.70 & 70 \\
S2 & 1.0 & 0.4 & 0.6 & 60 \\
S3 & 1.0 & 0.5 & 0.5 & 50 \\
S4 & 1.5 & 0.5 & 1.0 & 70 \\
S5 & 1.5 & 0.6 & 0.9 & 60 \\
S6 & 1.5 & 0.7 & 0.8 & 50 \\
\hline
\end{tabular}

Table 2 - Material specification of CoCrMo

\begin{tabular}{lllll}
\hline $\begin{array}{l}\text { Density } \\
\left(\mathrm{g} / \mathrm{cm}^{3}\right)\end{array}$ & $\begin{array}{l}\text { Young } \\
\text { Modulus } \\
(\mathrm{GPa})\end{array}$ & $\begin{array}{l}\text { Poisson } \\
\text { ratio }\end{array}$ & $\begin{array}{l}\text { Yield } \\
\text { strength } \\
(\mathrm{MPa})\end{array}$ & $\begin{array}{l}\text { Ultimate } \\
\text { strength } \\
(\mathrm{MPa})\end{array}$ \\
\hline 8.29 & 220 & 0.3 & 880 & 1150 \\
\hline
\end{tabular}

\subsection{Compression Testing}

From each design point in the design space (Table 1), one sample was randomly selected and compression using quasi static compression machine with $50 \mathrm{kN}$ load and a constant strain rate of $0.01 \mathrm{~s}^{-1}$. Five replicated for each design solution. The ISO-13314 standard was followed to determine the samples elastic modulus. The elastic modulus, yield and ultimate strength of the samples were determined from the stress-strain curves. The yield strength was measured using $0.2 \%$ offset method based on the first maximum compressive strength was recorded.
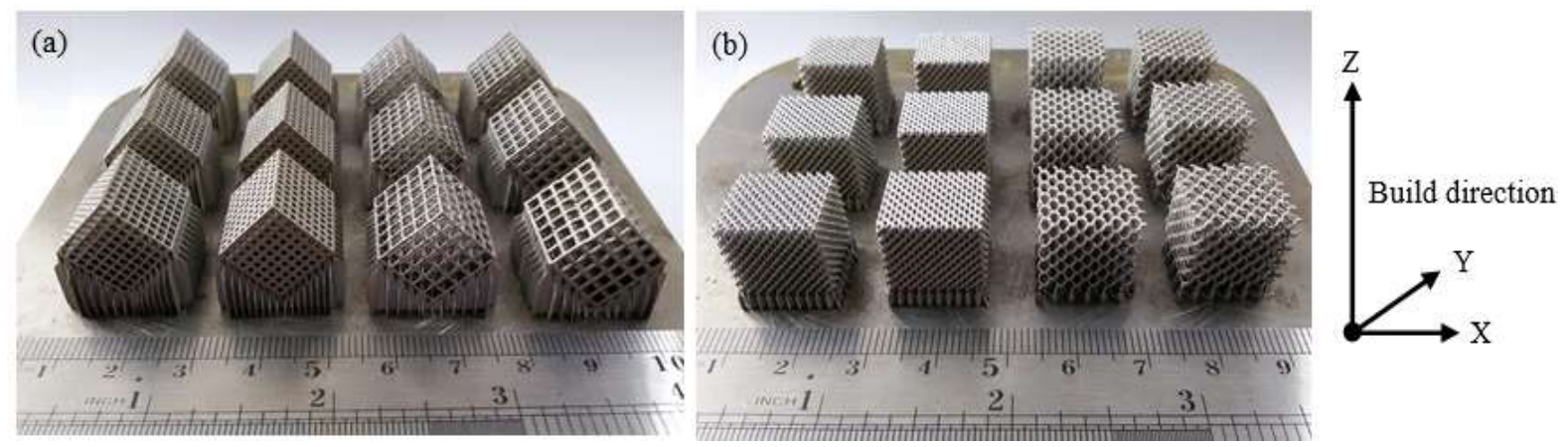

Fig. 1 - Manufactured samples with build direction

\section{Results And Discussion}

\subsection{Effective Elastic Modulus}

The effective elastic modulus was obtained from the mathematical calculation for each designed structure. Table 3 shows the effective elastic modulus of each structure obtained from Ashby and Gibson equation model. The highest $\mathrm{E}_{\text {eff }}$ for diamond type structures is $46.55 \mathrm{GPa}$ with porosity of $54 \%$ for sample D7. Meanwhile the lowest $\mathrm{E}_{\text {eff }}$ for diamond type is $7.13 \mathrm{GPa}$ with porosity of $82 \%$ for sample D1 and D4. The highest $\mathrm{E}_{\text {erf }}$ for square type is $55 \mathrm{GPa}$ with porosity $50 \%$ for sample S6 and the lowest $\mathrm{E}_{\text {eff }}$ is $19.8 \mathrm{GPa}$ with porosity of $70 \%$ for sample S1 and S4. The samples including 
D3, S3 and S6 exhibited lower porosity due to more dense and larger struts size compared to other samples. The $\mathrm{E}_{\text {eff }}$ of the selected designed samples were directly proportional to the volume porosity.

Fig. 3 shows the relationship between porosity and effective elastic modulus using Gibson and Ashby model for both sample types with a comparison of $\mathrm{E}_{\mathrm{eff}}$ obtained from previous study. The Eeff is decreased toward increasing of porosity percentage. Interestingly, the $\mathrm{E}_{\mathrm{eff}}$ obtained with porosity higher than $60 \%$ are closer and in range of mechanical properties of human bone (1-30 GPa). Thus, samples D1, S3 and S6 obtained E eff that out of the range of human bone properties.

\subsection{Finite Element Analysis}

An ANSYS Workbench program (ANSYS, USA) was utilized to predict the equivalent stress and elastic modulus of the selected designs. The simulation results of designed structures were validated with experimental values. Table 4 summarizes the average effective elastic modulus from finite element analysis.

Table 3 - Effective elastic modulus using Gibson and Ashby model

\begin{tabular}{lll}
\hline Sample & Porosity $(\%)$ & $\begin{array}{l}\text { Effective elastic modulus, } \\
\text { Eff }(\mathrm{GPa})\end{array}$ \\
\hline D1 & 82 & 7.13 \\
D2 & 70 & 19.80 \\
D3 & 58 & 35.20 \\
D4 & 80 & 7.12 \\
D5 & 74 & 16.04 \\
D6 & 66 & 26.95 \\
D7 & 54 & 46.55 \\
S1 & 70 & 19.80 \\
S2 & 60 & 30.40 \\
S3 & 50 & 55.00 \\
S4 & 70 & 19.80 \\
S5 & 60 & 30.40 \\
S6 & 50 & 55.0 \\
\hline
\end{tabular}




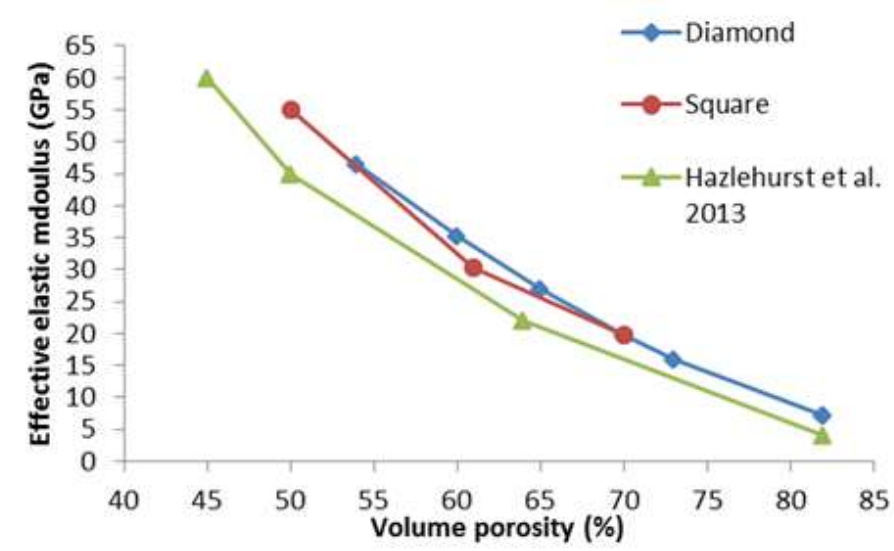

Fig. 3 - Relationship of volume porosity and effective elastic modulus of sample

According to finite element analysis, the $\mathrm{E}_{\mathrm{eff}}$ of diamond type was in range of $3.01 \mathrm{GPa}$ to $4.79 \mathrm{GPa}$. Meanwhile, the elastic modulus of square type was in range of $6.34 \mathrm{GPa}$ to $28.75 \mathrm{GPa}$. All samples for diamond square were in the range of mechanical properties of cancellous bone properties (1-15 GPa). More samples of square type exhibited elastic modulus similar to cortical bone properties (15-30 GPa) except for sample S1 and S4 which were in the range of cancellous bone. The results show the pore structure can tailor the elastic modulus from the porosity value and different pore shape may produce more predictable mechanical compressive behavior.

Table 4 - Effective elastic modulus using finite element analysis

\begin{tabular}{ll}
\hline Sample & $\begin{array}{l}\text { Effective elastic } \\
\text { modulus, } \mathrm{E}_{\text {eff }}(\mathrm{GPa})\end{array}$ \\
\hline $\mathrm{D} 1$ & 3.48 \\
D2 & 3.79 \\
D3 & 4.79 \\
D4 & 3.01 \\
D5 & 3.58 \\
D6 & 4.10 \\
D7 & 3.92 \\
S1 & 8.77 \\
S2 & 15.77 \\
S3 & 27.71 \\
S4 & 6.34 \\
S5 & 28.75 \\
S6 & 27.44 \\
\hline
\end{tabular}

Both type of structures were deformed with same failure mechanism whereas their possessed different volume fractions. Deformation mechanism represented plasticity for square and diamond type structures with $10 \%$ strains in Fig. 4 and Fig. 5, respectively. It can be seen that the deformation commenced from the top and then, the collapse of the 
each layer of the cell continuously. The homogeneity of failure mechanism was indicated to potential of high impact resistance from the struts of the samples [40]. Since struts of the structures withstand axial deformation owing to their parallel direction relative to the loading, buckling micro-struts was expected owing to high release of energy as each stage of collapse [41].

Stress fluctuation was explained by failure of each layer shown in Fig. 4 (b) and Fig. 5(b). Failure in diamond type structures was seen to be accompanied by shearing of the micro struts leading the structure to tend to bending dominated deformation. Crushing of struts towards central plates led to the development of a continuous shear band of $45^{\circ}$ around the model Fig.5 (b). Thus, it is deduced the less energy was released at the stage of failure of diamond type as a result of strut inclination compared the buckling mechanism in square type structures. It can be inferred from the results that the micro- strut orientation plays crucial role in deformation mechanism and consequently in stress strain behavior of scaffolds [41].

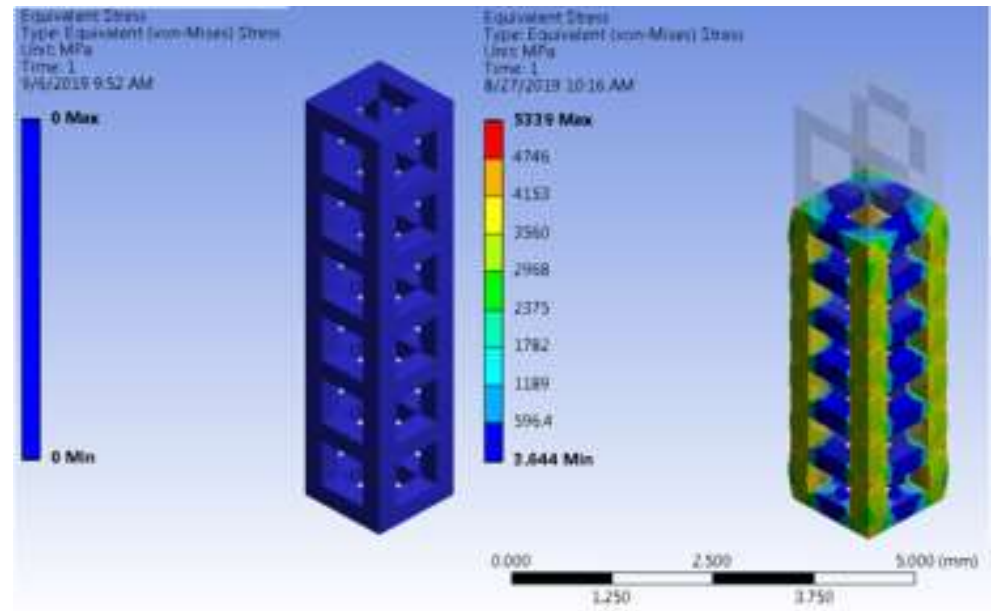

Fig. 4 - Deformation mechanism of square type structures shows buckling effect

It is worth noting that the FEA model was developed for a fundamental study of deformation in porous structures and mainly emphasized the default options available in ANSYS structural module. FEA model used in numerical study was based on ideal geometry while the manufactured struts surfaces might be irregular. This could lead to imperfections either acting as stress concentrators or providing additional material to struts by counteracting compressive load in the manufactured structures [38]. Moreover, the porosity and surface roughness might also affect the mechanical response of the porous structure of manufactured samples but those parameters were not considered in the FEA model [42].

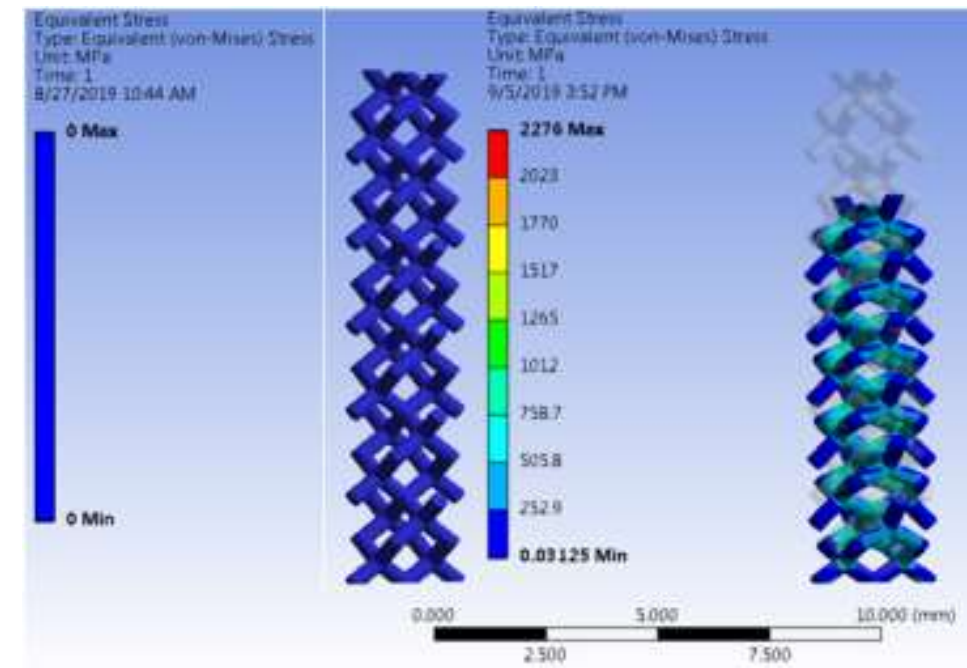

Fig. 5 - Deformation mechanism of square type structures shows buckling effect 


\subsection{Mechanical Properties of Structures}

Compression mechanical properties were obtained by experiment and compared with effective elastic modulus obtained by finite element analysis for validation. Three selected designed structures namely D2, D5 and S5. Fig. 6 shows the elastic modulus obtained from experimental and simulation of these selected designed structures. The details mechanical properties of selected structures were summarised in Table 5.

All the experimental results for the selected samples show lower elastic modulus compared to results from finite element analysis and Gibson and Ashby equation model. The elastic modulus obtained from experimental was in the range of $2.29 \mathrm{GPa}$ to $8.75 \mathrm{GPa}$ and were closer for cancellous bone properties. However, the experimental results were in good agreement with results obtained from finite element analysis. It is show that modelling approach in this work has provided helpful justification the theory that can have significant effect on the mechanical properties of the structures. In addition, mesh sensitivity might plays important role in the accuracy of finite element model [43]. Thus, mesh sensitivity analysis is suggested to carry out in the future work.

The stress-strain curves of the compression tests for the selected samples were shown in Fig. 7. The samples experienced an initial settling period represented plateau stress which is show as non-linear and concave upwards line. The structures continue to deform at a nearly constant plateau stress until the structures were collapsed. The deformation occurred shown the elastic-plastic behaviour which is indicated the ductility and brittleness of the structures [44]. The stress strain illustrated the typical bending-dominated structures. The selected structures were tougher and ductile and capable to absorb energy during loading impact and higher resistance to plastic buckling [45, 46]. The large area of deformation is obtained especially for S5 due bigger than other structure due the larger strut size of $0.6 \mathrm{~mm}$. Consequently influences higher modulus of toughness that was in range of $41 \mathrm{MJ} / \mathrm{m}^{3}$ to $235.64 \mathrm{MJ} / \mathrm{m}^{3}$.

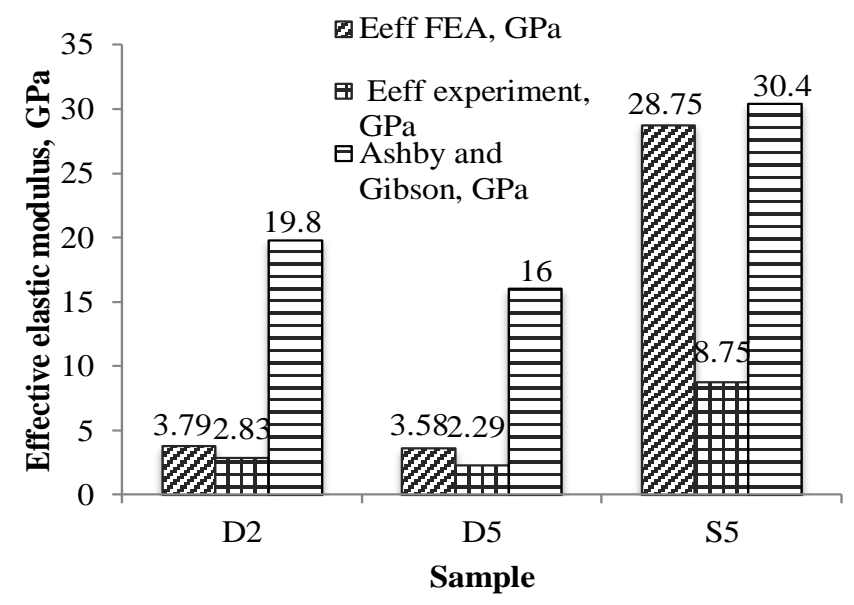

Fig. 6 - Comparison of the values for the effective elastic modulus

The stress-strain curves obtained from this study did not have and densification region due to typical elastic-plastic deformation has been observed [47-49]. The densification after plastic region observed in metallic cellular structures by Gibson and Ashby [50] under uniaxial loading was not observed in this study. This might be attributed to the brittle behaviours of the strut before the densification begins, which is in agreement with the findings by Gümrük, et al. [51], Limmahakhun, et al. [52] and McKown, et al. [53].

Table 5 - Mechanical properties of selected structures

\begin{tabular}{lllll}
\hline Sample & $\begin{array}{l}0.2 \% \text { yield } \\
\text { strength, } \\
\text { MPa }\end{array}$ & $\begin{array}{l}\text { Ultimate } \\
\text { compression } \\
\text { strength, MPa }\end{array}$ & $\begin{array}{l}\text { Modulus } \\
\text { of } \\
\text { resilience } \\
\left(\mathrm{MJ} / \mathrm{m}^{3}\right)\end{array}$ & $\begin{array}{l}\text { Modulus } \\
\text { of } \\
\text { toughness } \\
\left(\mathrm{MJ}^{3} \mathrm{~m}^{3}\right)\end{array}$ \\
\hline D2 & $52.4 \pm 2.65$ & $85.15 \pm 3.97$ & 5.48 & 63.40 \\
D5 & $41.3 \pm 1.64$ & $63.2 \pm 0.99$ & 10.43 & 41.14 \\
S5 & $111.3 \pm 3.61$ & $261.01 \pm 2.36$ & 8.22 & 235.64 \\
\hline
\end{tabular}




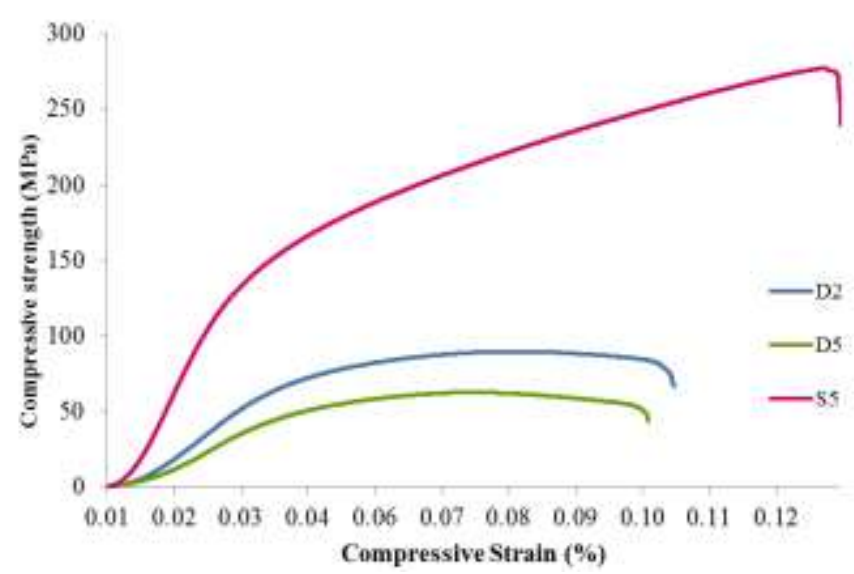

Fig. 7 - Stress strain curves of selected samples

\section{Conclusion}

In treating skeletal fractures affected by road traffic accidents, replacement or generation of lost bone requires the orthopedic implants to be designed using design space tool. Design space is a tool to visualize and understand the role of cell topology including unit cell size, pore size, porosity, and strut thickness as the function of design parameters controlling of porous structures. Design space in this research has been used in studying the relationship of the interplay of cell topology based of square and diamond unit cell, bone ingrowth requirement and manufacturing limitation influencing the design of porous structured with desired properties for bone scaffold. It is found that pore size bigger than $50 \mu \mathrm{m}$ with porosity higher than $50 \%$ are favourable for bone in growth requirement and additive manufacturing technology is limited to produce strut thickness smaller than $200 \mu \mathrm{m}$.

FEA in bone implant modelling is a numerical simulation approach to evaluate the behaviour of various design models on the stress under compressive condition. By simplifying the FEA model to reduce time of analysis, FEA has analysed the von Mises and effective elastic modulus was calculated. It is found that effective elastic modulus in the range of $3 \mathrm{GPa}$ to $4.8 \mathrm{GPa}$ for diamond type and the range of $6 \mathrm{GPa}$ to $28.8 \mathrm{GPa}$ for square type. Square and diamond unit cell shapes are represented bending-dominated and stretch-dominated of porous structures.

In this study, three samples namely D2, D5 and S5 made of CoCrMo and produced by AM have been tested mechanically under compression loading. It is found that the calculated elastic modulus was $2.8 \mathrm{GPa}$ for D2, $2.3 \mathrm{GPa}$ for D5 and 8.8 GPa for S5. The observed elastic modulus was in similar to cancellous bone properties. Within the limitation of the study, the cost and time effective FEA approach did reflect the true mechanical properties of an infinite structure of CoCrMo scaffold with the average error of $13 \%$ for diamond and for $35 \%$ for square. This study assists researcher to explore new bioinspired geometries that can be used for metallic scaffold manufactured by additive manufacturing. Future work can focus on more design parameters of different unit cell shape for early step in implant design to eliminate stress shielding and stimulate bone ingrowth for performing biological testing, static and dynamic analysis on the structures.

\section{Acknowledgement}

The authors are grateful to the Ministry of Higher Education Malaysia for financial support under fundamental research grants scheme FRGS/1/2016/TK03/UMP/02/17 and Universiti Malaysia Pahang, Malaysia (www.ump.edu.my) for financial supports given under RDU200301 and PGRS1903164.

\section{References}

[1] F. Alotaibi, A. H. Alqahtani, A. Alwadei, H. M. Al-raeh, I. Abusaq, S. A. Mufrrih, et al.(2021). "Pattern of orthopedic injuries among Victims of Road Traffic Accidents in Aseer region, Saudi Arabia," Annals of Medicine and Surgery, p. 102509

[2] L. Zhang, G. Yang, B. N. Johnson, and X. Jia,(2019). "Three-dimensional (3D) printed scaffold and material selection for bone repair," Acta Biomaterialia, vol. 84, pp. 16-33, 2019/01/15/ 2019

[3] G. Zhao, S. Li, X. Chen, X. Qu, R. Chen, Y. Wu, et al.,(2019). "Porous tantalum scaffold fabricated by gel casting based on 3D printing and electrolysis," Materials Letters, vol. 239, pp. 5-8, 2019/03/15/ 2019

[4] Z. A. Assiri, E. A. Almajid, and A. K. Alfadhel,(2020). "Retrospective radiological evaluation to study the prevalence and pattern of maxillofacial fracture among Military personal at Prince Sultan Military Medical City [PSMMC], Riyadh: An institutional study," The Saudi Dental Journal, vol. 32, pp. 242-249 
[5] N. S. Manam, W. S. W. Harun, D. N. A. Shri, S. A. C. Ghani, T. Kurniawan, M. H. Ismail, et al.,(2017). "Study of corrosion in biocompatible metals for implants: A review," Journal of Alloys and Compounds, vol. 701, pp. 698-715, 2017/04/15/2017

[6] P. Stenlund, S. Kurosu, Y. Koizumi, F. Suska, H. Matsumoto, A. Chiba, et al.,(2015). "Osseointegration Enhancement by $\mathrm{Zr}$ doping of Co-Cr-Mo Implants Fabricated by Electron Beam Melting," Additive Manufacturing, vol. 6, pp. 6-15, 2015/04/01/2015

[7] X. P. Tan, Y. J. Tan, C. S. L. Chow, S. B. Tor, and W. Y. Yeong,(2017). "Metallic powder-bed based 3D printing of cellular scaffolds for orthopaedic implants: A state-of-the-art review on manufacturing, topological design, mechanical properties and biocompatibility," Materials Science and Engineering: C, vol. 76, pp. 1328-1343, 2017

[8] X. Wang, S. Xu, S. Zhou, W. Xu, M. Leary, P. Choong, et al.,(2016). "Topological design and additive manufacturing of porous metals for bone scaffolds and orthopaedic implants: A review," Biomaterials, vol. 83, pp. 127-141, 2016

[9] Z. Wang, C. Wang, C. Li, Y. Qin, L. Zhong, B. Chen, et al.,(2017). "Analysis of factors influencing bone ingrowth into three-dimensional printed porous metal scaffolds: A review," Journal of Alloys and Compounds, vol. 717, pp. 271-285, 2017/09/15/2017

[10] R. A. Perez and G. Mestres,(2016). "Role of pore size and morphology in musculo-skeletal tissue regeneration," Materials Science and Engineering: C, vol. 61, pp. 922-939, 2016/04/01/ 2016

[11] B. Feng, Z. Jinkang, W. Zhen, L. Jianxi, C. Jiang, L. Jian, et al.,(2011). "The effect of pore size on tissue ingrowth and neovascularization in porous bioceramics of controlled architecture in vivo," Biomedical Materials, vol. 6, p. 015007

[12] S. M. M. Roosa, J. M. Kemppainen, E. N. Moffitt, P. H. Krebsbach, and S. J. Hollister,(2010). "The pore size of polycaprolactone scaffolds has limited influence on bone regeneration in an in vivo model," Journal of Biomedical Materials Research Part A: An Official Journal of The Society for Biomaterials, The Japanese Society for Biomaterials, and The Australian Society for Biomaterials and the Korean Society for Biomaterials, vol. 92, pp. 359-368

[13] M.-C. von Doernberg, B. von Rechenberg, M. Bohner, S. Grünenfelder, G. H. van Lenthe, R. Müller, et al.,(2006). "In vivo behavior of calcium phosphate scaffolds with four different pore sizes," Biomaterials, vol. 27, pp. 5186-5198, 2006/10/01/ 2006

[14] C. M. Murphy, M. G. Haugh, and F. J. O'brien,(2010). "The effect of mean pore size on cell attachment, proliferation and migration in collagen-glycosaminoglycan scaffolds for bone tissue engineering," Biomaterials, vol. 31, pp. 461-466

[15] G.-I. Im, J.-Y. Ko, and J. H. Lee,(2012). "Chondrogenesis of adipose stem cells in a porous polymer scaffold: influence of the pore size," Cell transplantation, vol. 21, pp. 2397-2405

[16] F. J. O’Brien, B. A. Harley, I. V. Yannas, and L. J. Gibson, (2005)."The effect of pore size on cell adhesion in collagen-GAG scaffolds," Biomaterials, vol. 26, pp. 433-441

[17] S. Barui, S. Chatterjee, S. Mandal, A. Kumar, and B. Basu, (2017)."Microstructure and compression properties of 3D powder printed Ti-6Al-4V scaffolds with designed porosity: Experimental and computational analysis," Materials Science and Engineering: C, vol. 70, pp. 812-823, 2017/01/01/ 2017

[18] Q. Ran, W. Yang, Y. Hu, X. Shen, Y. Yu, Y. Xiang, et al.,(2018). "Osteogenesis of 3D printed porous Ti6Al4V implants with different pore sizes," Journal of the Mechanical Behavior of Biomedical Materials, vol. 84, pp. 1$11,2018 / 08 / 01 / 2018$

[19] D. Zhao, Y. Huang, Y. Ao, C. Han, Q. Wang, Y. Li, et al.,(2018). "Effect of pore geometry on the fatigue properties and cell affinity of porous titanium scaffolds fabricated by selective laser melting," Journal of the Mechanical Behavior of Biomedical Materials, vol. 88, pp. 478-487, 2018/12/01/ 2018

[20] H. Zhao, L. Li, S. Ding, C. Liu, and J. Ai,(2018). "Effect of porous structure and pore size on mechanical strength of 3D-printed comby scaffolds," Materials Letters, vol. 223, pp. 21-24, 2018/07/15/ 2018.

[21] S. Arabnejad, R. Burnett Johnston, J. A. Pura, B. Singh, M. Tanzer, and D. Pasini,(2016). "High-strength porous biomaterials for bone replacement: A strategy to assess the interplay between cell morphology, mechanical properties, bone ingrowth and manufacturing constraints," Acta Biomaterialia, vol. 30, pp. 345-356

[22] D. Melancon, Z. S. Bagheri, R. B. Johnston, L. Liu, M. Tanzer, and D. Pasini,(2017). "Mechanical characterization of structurally porous biomaterials built via additive manufacturing: experiments, predictive models, and design maps for load-bearing bone replacement implants," Acta Biomaterialia, vol. 63, pp. 350-368, 2017/11/01/ 2017

[23] Du Plessis, C. Broeckhoven, I. Yadroitsava, I. Yadroitsev, C. H. Hands, R. Kunju, et al.,(2019). "Beautiful and Functional: A Review of Biomimetic Design in Additive Manufacturing," Additive Manufacturing, vol. 27, pp. 408-427, 2019/05/01/2019

[24] Wubneh, E. K. Tsekoura, C. Ayranci, and H. Uludağ,(2018). "Current state of fabrication technologies and materials for bone tissue engineering," Acta Biomaterialia, vol. 80, pp. 1-30, 2018/10/15/ 2018

[25] Bružauskaite, D. Bironaite, E. Bagdonas, and E. Bernotienè,(2016). "Scaffolds and cells for tissue regeneration: different scaffold pore sizes-different cell effects," Cytotechnology, vol. 68, pp. 355-369 
[26] M. Murphy and F. J. O'Brien, "Understanding the effect of mean pore size on cell activity in collagenglycosaminoglycan scaffolds,"(2010). Cell adhesion \& migration, vol. 4, pp. 377-381, Jul-Sep 2010

[27] S. Van Bael, G. Kerckhofs, M. Moesen, G. Pyka, J. Schrooten, and J. P. Kruth,(2011). "Micro-CT-based improvement of geometrical and mechanical controllability of selective laser melted Ti6Al4V porous structures," Materials Science and Engineering: A, vol. 528, pp. 7423-7431

[28] M. Jiménez, L. Romero, I. A. Domínguez, M. d. M. Espinosa, and M. Domínguez,(2019). "Additive Manufacturing Technologies: An Overview about 3D Printing Methods and Future Prospects," Complexity, vol. 2019

[29] M. Dumas, P. Terriault, and V. Brailovski,(2017). "Modelling and characterization of a porosity graded lattice structure for additively manufactured biomaterials," Materials \& Design, vol. 121, pp. 383-392

[30] G. Maîtrejean, P. Terriault, and V. Brailovski,(2013). "Density dependence of the macroscale superelastic behavior of porous shape memory alloys: a two-dimensional approach," Smart Materials Research, vol. 2013.

[31] L. Wang, J. Kang, C. Sun, D. Li, Y. Cao, and Z. Jin,(2017). "Mapping porous microstructures to yield desired mechanical properties for application in 3D printed bone scaffolds and orthopaedic implants," Materials \& Design, vol. 133, pp. 62-68, 2017/11/05/ 2017

[32] H. Gao, X. Li, C. Wang, P. Ji, and C. Wang,(2019). "Mechanobiologically optimization of a 3D titanium-mesh implant for mandibular large defect: A simulated study," Materials Science and Engineering: C, vol. 104, p. 109934, 2019/11/01/ 2019

[33] M. Williams, A. Adewunmi, R. M. Schek, C. L. Flanagan, P. H. Krebsbach, S. E. Feinberg, et al.,(2005). "Bone tissue engineering using polycaprolactone scaffolds fabricated via selective laser sintering," Biomaterials, vol. 26, pp. 4817-4827

[34] S. J. Lee, I. W. Lee, Y. M. Lee, H. B. Lee, and G. Khang,(2004). "Macroporous biodegradable natural/synthetic hybrid scaffolds as small intestine submucosa impregnated poly (D, L-lactide-co-glycolide) for tissue-engineered bone," Journal of Biomaterials Science, Polymer Edition, vol. 15, pp. 1003-1017

[35] V. Karageorgiou and D. Kaplan,(2005). "Porosity of 3D biomaterial scaffolds and osteogenesis," Biomaterials, vol. 26, pp. 5474-5491

[36] G. Miranda, S. Faria, F. Bartolomeu, E. Pinto, N. Alves, N. Peixinho, et al.,(2019). "A study on the production of thin-walled Ti6Al4V parts by selective laser melting," Journal of Manufacturing Processes, vol. 39, pp. 346-355, 2019/03/01/ 2019

[37] E. Abele, H. A. Stoffregen, M. Kniepkamp, S. Lang, and M. Hampe,(2015). "Selective laser melting for manufacturing of thin-walled porous elements," Journal of Materials Processing Technology, vol. 215, pp. 114$122,2015 / 01 / 01 / 2015$

[38] S. J. Al-Saedi, S. H. Masood, M. Faizan-Ur-Rab, A. Alomarah, and P. Ponnusamy,(2018). "Mechanical properties and energy absorption capability of functionally graded F2BCC lattice fabricated by SLM," Materials \& Design, vol. 144, pp. 32-44, 2018/04/15/ 2018

[39] Hazlehurst, C. J. Wang, and M. Stanford,(2013). "Evaluation of the stiffness characteristics of square pore CoCrMo cellular structures manufactured using laser melting technology for potential orthopaedic applications," Materials \& Design, vol. 51, pp. 949-955

[40] Rashed, M. Ashraf, R. Mines, and P. J. Hazell,(2016). "Metallic microlattice materials: A current state of the art on manufacturing, mechanical properties and applications," Materials \& Design, vol. 95, pp. 518-533

[41] J. Kadkhodapour, H. Montazerian, A. C. Darabi, A. P. Anaraki, S. M. Ahmadi, A. A. Zadpoor, et al.,(2015). "Failure mechanisms of additively manufactured porous biomaterials: Effects of porosity and type of unit cell," Journal of the Mechanical Behavior of Biomedical Materials, vol. 50, pp. 180-191, 2015/10/01/2015

[42] P. Wang, H. Lei, X. Zhu, H. Chen, and D. Fang,(2019). "Influence of manufacturing geometric defects on the mechanical properties of AlSi10Mg alloy fabricated by selective laser melting," Journal of Alloys and Compounds, vol. 789, pp. 852-859, 2019/06/15/ 2019

[43] F. Genna, (2019)."On the sensitivity of Finite Element results in the calculation of the lateral thrust for all-steel buckling-restrained braces," Engineering Structures, vol. 194, pp. 66-76, 2019/09/01/ 2019

[44] Yang, R. Mertens, M. Ferrucci, C. Yan, Y. Shi, and S. Yang,(2019). "Continuous graded Gyroid cellular structures fabricated by selective laser melting: Design, manufacturing and mechanical properties," Materials \& Design, vol. 162, pp. 394-404, 2019/01/15/ 2019

[45] L. Chen, J. Zhang, B. Du, H. Zhou, H. Liu, Y. Guo, et al.,(2018). "Dynamic crushing behavior and energy absorption of graded lattice cylindrical structure under axial impact load," Thin-Walled Structures, vol. 127, pp. 333-343, 2018/06/01/2018

[46] Cetin and C. Baykasoğlu,(2019). "Energy absorption of thin-walled tubes enhanced by lattice structures," International Journal of Mechanical Sciences, vol. 157-158, pp. 471-484, 2019/07/01/ 2019

[47] L. Xiao, W. Song, C. Wang, H. Tang, Q. Fan, N. Liu, et al., (2017)."Mechanical properties of open-cell rhombic dodecahedron titanium alloy lattice structure manufactured using electron beam melting under dynamic loading," International Journal of Impact Engineering, vol. 100, pp. 75-89 
[48] Maskery, N. Aboulkhair, A. Aremu, C. Tuck, I. Ashcroft, R. D. Wildman, et al.,(2016). "A mechanical property evaluation of graded density Al-Si10-Mg lattice structures manufactured by selective laser melting," Materials Science and Engineering: A, vol. 670, pp. 264-274

[49] Y. Liu, S. Li, H. Wang, W. Hou, Y. Hao, R. Yang, et al.,(2016). "Microstructure, defects and mechanical behavior of beta-type titanium porous structures manufactured by electron beam melting and selective laser melting," Acta Materialia, vol. 113, pp. 56-67

[50] L. J. Gibson,(2005). "Biomechanics of cellular solids," Journal of biomechanics, vol. 38, pp. 377-399

[51] R. Gümrük, R. Mines, and S. Karadeniz,(2013). "Static mechanical behaviours of stainless steel micro-lattice structures under different loading conditions," Materials Science and Engineering: A, vol. 586, pp. 392-406

[52] S. Limmahakhun, A. Oloyede, K. Sitthiseripratip, Y. Xiao, and C. Yan,(2017). "Stiffness and strength tailoring of cobalt chromium graded cellular structures for stress-shielding reduction," Materials \& Design, vol. 114, pp. 633641, 2017

[53] S. McKown, Y. Shen, W. Brookes, C. Sutcliffe, W. Cantwell, G. Langdon, et al.,(2008). "The quasi-static and blast loading response of lattice structures," International Journal of Impact Engineering, vol. 35, pp. 795-810, 2008 